\title{
EXAFS study of Ag-As-Se and Ag-As-S ionic conductor glasses
}

\author{
V. MASTELARO*, S. BÉNAZETH ${ }^{* * * *}$ and H. DEXPERT ${ }^{*}$ \\ *LURE, Université Paris Sud, 91405 Orsay Cedex, France \\ ${ }^{*}$ Lab. de Chimie Minérale Structurale, Université Paris V, 75006 Paris, France
}

The local structure of glasses that belong to the $\left(\mathrm{Ag}_{2} \mathrm{Se}\right)_{\mathrm{x}}(\mathrm{AsSe})_{1-\mathrm{x}}(\mathrm{L} 1$ line $),\left(\mathrm{Ag}_{2} \mathrm{~S}\right)_{\mathrm{x}}\left(\mathrm{As}_{2} \mathrm{~S}_{3}\right)_{1-\mathrm{x}}$ (L2 line) and $\left(\mathrm{Ag}_{2} \mathrm{Se}\right)_{\mathbf{x}}\left(\mathrm{As}_{2} \mathrm{Se}_{3}\right)_{1-\mathrm{x}}(\mathrm{L} 3$ line) have been studied using $\mathrm{X}$ ray absorption spectroscopy (XAS). The arsenic atoms are three coordinated for all glassy compositions. However, for L2 and L3 line glasses we observed an evolution of the Debye-Waller factor around these atoms, whereas this parameter is constant for L1 line glasses. This is explained by the existence of As-As homopolar bonds in L1 line glasses that block the structure. The same behaviour is observed for the surroundings of the silver atoms. The vitreous transition temperature and the electrical characteristics are reported and analyzed relatively to the structural results.

\section{I- Introduction}

The ternary chalcogenide glasses based on the Ag-As-Se and Ag-As-S systems are good ionic conductors, with silver as mobile cation [1]. Moreover, the photodissolution of $\mathrm{Ag}$ in $\mathrm{As}_{2} \mathrm{Se}_{3}$ and $\mathrm{As}_{2} \mathrm{~S}_{3}$ thin films are interesting materials for applications in VLSI circuits [2,3]. Although their physical properties have been widely studied, there are few reports on their structural properties, especially for compositions with large quantities of silver. Knowledge of the local structure of these glasses is certainly essential for the understanding of the conduction processes from a microscopic point of view. We have previously analyzed and discussed $\mathrm{X}$ ray absorption spectroscopy (XAS) of $\left(\mathrm{Ag}_{2} \mathrm{Se}\right)_{\mathrm{X}}(\mathrm{AsSe})_{1-\mathrm{x}}$ ( $\mathrm{L1}$ line) and $\left(\mathrm{Ag}_{2} \mathrm{~S}\right)_{x}\left(\mathrm{As}_{2} \mathrm{~S}_{3}\right)_{1-\mathrm{x}}$ (L2 line) $(0.10 \leq \mathrm{x} \leq 0.80)$ glasses [4,5]. However, it was not easy to relate the structural results with the physical properties because the glassy compositions investigated belong to two different lines of the respective phase diagrams, the anion concentration being higher for sulphide glasses. We have now performed EXAFS studies at silver, selenium and arsenic $\mathrm{K}$ edges (room temperature experiments) for glasses that belong to the $\left(\mathrm{Ag}_{2} \mathrm{Se}\right)_{x}\left(\mathrm{As}_{2} \mathrm{Se}_{3}\right)_{1-\mathrm{x}}$ line ( $\mathrm{L} 3$ line) with $0.10 \leq \mathrm{x}$ $\leq 0.75$, which is the selenide homologous line of the $\mathrm{L} 2$ sulphide line. The L3 and L2 line results are quite identical and therefore we discuss the L3 line results here. In this paper we compare the L3 line results with those of the previous $\mathrm{L} 1$ line, and the structural results are related to physical properties as $\mathrm{Tg}$ and ionic conductivity. 


\section{II- Experimental and data analysis}

The synthesis of these glasses was performed following two procedures:

i- For the selenide (all compositions) and sulphide glasses with $\mathrm{x}<0.67$, we used a conventional high temperature melting $\left(900^{\circ} \mathrm{C}\right)$. A cold water quenching is then applied;

ii- for sulphide glasses with $x \geq 0.67$, we used, after the melt, a twin roller apparatus [6].

In both cases, the vitreous state of the samples was confirmed by $\mathrm{X}$ ray diffraction experiments. The transmission EXAFS measurements were made on the D.C.I. storage ring, at LURE - Orsay, operating at $1.85 \mathrm{GeV}$ with a $250 \mathrm{~mA}$ average current. The EXAFS data analysis has been described elsewhere in a previous work [5]. The backscattering amplitudes and phase shifts for As - (Se,S), Se $(\mathrm{As}, \mathrm{Ag})$ and $\mathrm{Ag}$ - $(\mathrm{Se}, \mathrm{S})$ were obtained using crystalline compounds as references: $\mathrm{As}_{2}(\mathrm{Se}, \mathrm{S})_{3}$, $\mathrm{Ag}_{3} \mathrm{As}$ (Se,S) $)_{3}$ and $\mathrm{CdSe}$ (Cd playing the role of silver). The error bar of the results presented here is estimated at nearly $\pm 10 \%$ atoms for the neighbours number $N$ and $\pm 0.01 \AA$ for the mean bond length $R$.

\section{III- Results and discussion of EXAFS experiments}

\section{III.1- Comparison of $\mathrm{L} 1$ and $\mathrm{L3}$ selenide glasses lines.}

\section{III.1.A - Arsenic K edge results}

Figure 1 shows the Fourier transform moduli of $\mathrm{k}^{3}$ weighted EXAFS spectra for the arsenic atom. Only one shell is observed for the glasses as well as for the $\mathrm{Ag}_{3} \mathrm{AsSe}_{3}$ reference compound (a).

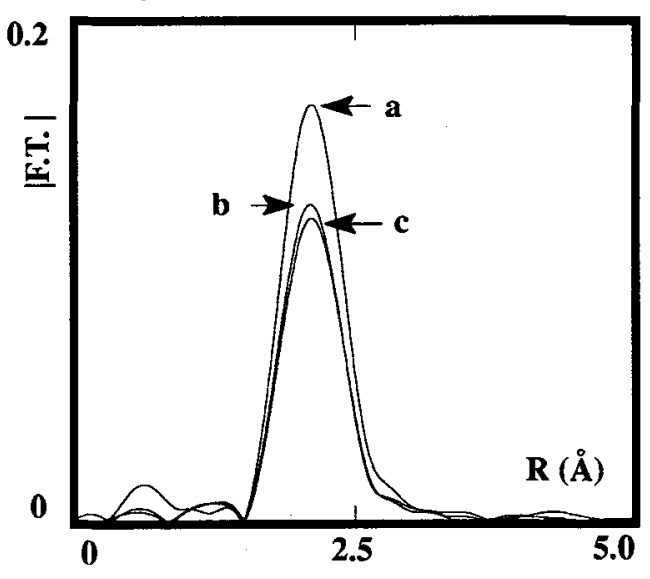

[L1]

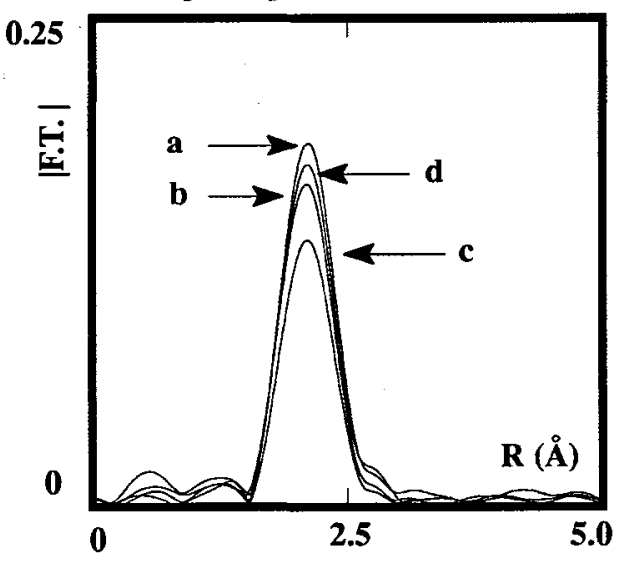

[L3]

Figure 1- Fourier transform magnitude (uncorrected for phase shift) at the arsenic K edge: [L1] selenide glasses: a: $\mathrm{Ag}_{3} \mathrm{AsSe}_{3}$ crystal, b: $\mathrm{x}=0.11$ and c: $\mathrm{x}=0.43$; [L3] selenide glasses: $\mathrm{a}: \mathrm{Ag}_{3} \mathrm{AsSe}_{3}$ crystal, $b: x=0.10, c: x=0.60$ and $d: x=0.75$.

The fitting results (Table Ia and Ib) show that the arsenic atom is coordinated by three selenium atoms ( substituted by some arsenic atoms for L1 line) whatever the silver composition and the selenide glass line. However, we observe for the L3 glasses, that the Debye-Waller factor $(\Delta \sigma)$ presents a maximum value for the $x=0.60$ composition, the minimun being reached for $x=0.75$. An explanation of this effect may be proposed by the analysis of the local order in the two crystalline phases that belong to this line and are close to these glassy compositions: $\mathrm{AgAsSe}_{2}$ (close to $\mathrm{x}=0.60$ ) and $\mathrm{Ag}_{3} \mathrm{AsSe}_{3}$ (equal to $\mathrm{x}=0.75$ ). It has been shown previously that the disorder and the mean bond length around the arsenic 
atom is more important in the $\mathrm{AgAsSe}_{2}$ than in the $\mathrm{Ag}_{3} \mathrm{AsSe}_{3}$ [7]. Thus we remark that the $\mathrm{L} 3$ glasses present the same structural disorder behaviour as observed for the homologous crystalline phases.

Table Ia and Ib. Arsenic K edge: one shell fit: (a): selenide L1 glasses and (b): selenide L3 glasses. $\mathrm{x}$ is the composition, $\mathrm{N}$ is the neighbour number, $\mathrm{R}$ the mean interatomic distance, $\Delta \sigma$ the Debye-Waller factor and $\Delta \mathrm{E}$ the $\mathrm{K}$-shell energy variation.

(a) L1 line

\begin{tabular}{|ccccc|}
\hline \multicolumn{2}{|c|}{$\mathrm{N}_{\text {As-Se }}$} & $\begin{array}{c}\mathrm{R}_{\text {As-Se }} \Delta \sigma_{\text {As-Se }} \\
(\AA)\end{array}$ & $\begin{array}{c}\Delta \mathrm{E} \\
(\AA)\end{array}$ & $\mathrm{eV}$ \\
\hline 0.11 & 2.9 & 2.42 & 0.041 & -1.2 \\
0.18 & 3.0 & 2.42 & 0.044 & -1.3 \\
0.33 & 3.0 & 2.42 & 0.043 & -0.8 \\
0.43 & 3.0 & 2.42 & 0.041 & -1.2 \\
\hline
\end{tabular}

(b) L3 line

\begin{tabular}{|ccccc|}
\hline $\mathrm{x}$ & $\mathrm{N}_{\text {As-Se }}$ & $\begin{array}{l}\mathrm{R}_{\text {As-Se }} \\
(\AA)\end{array}$ & $\begin{array}{l}\Delta \sigma_{\text {As-Se }} \\
(\AA)\end{array}$ & $\begin{array}{c}\Delta \mathrm{E} \\
\mathrm{eV}\end{array}$ \\
\hline 0.10 & 3.0 & 2.41 & 0.026 & 0.9 \\
0.40 & 3.0 & 2.41 & 0.025 & -0.3 \\
0.50 & 3.0 & 2.41 & 0.030 & -0.4 \\
0.60 & 3.0 & 2.41 & 0.045 & -1.3 \\
0.75 & 3.0 & 2.41 & 0.020 & -0.6 \\
\hline
\end{tabular}

\section{III.1.B- Selenium K edge results}

Figure 2 shows the Fourier transform moduli of $\mathrm{k}^{3}$ weighted EXAFS spectra for the selenium atoms. The shoulder on the right side of the main peak is related to Se-Ag bonds.

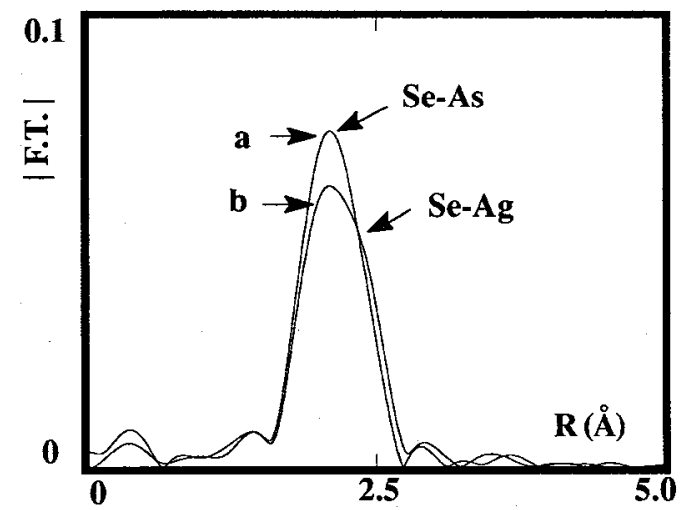

[L1]



[L3]

Figure 2 - Fourier transform moduli (uncorrect for phase shift) at the selenium K edge: [L1] selenide glasses: $a: x=0.11$ and $b: x=0.43$, [L3] selenide glasses: $a: x=0.10$ and $b: x=0.75$.

Table II. Selenium K edge:Results of a one shell fit for the selenide L3 and L1 glasses. $x$ is the composition, $N$ is the neighbour number, $R$ the mean interatomic distance, $\Delta \sigma$ the Debye-Waller factor and $\Delta \mathrm{E}$ the $\mathrm{K}$-shell energy variation.

\begin{tabular}{|ccccccccc|}
\hline $\mathrm{x}$ & $\mathrm{N}_{\text {Se-As }}$ & $\begin{array}{c}\mathrm{R}_{\text {Se-As }} \\
(\AA)\end{array}$ & $\begin{array}{c}\Delta \sigma_{\text {Se-As }} \\
(\AA)\end{array}$ & $\mathrm{N}^{\prime \prime}$ Se-Ag & $\begin{array}{c}\mathrm{R}_{\text {Se-Ag }} \\
(\AA)\end{array}$ & $\begin{array}{c}\Delta \sigma_{\text {Se-Ag }} \\
(\AA)\end{array}$ & $\begin{array}{c}\Delta \mathrm{E} \\
(\mathrm{eV})\end{array}$ & $\mathrm{N}^{\prime}+\mathrm{N}^{\prime \prime}$ \\
\hline $0.11(\mathrm{~L} 1)$ & 1.7 & 2.40 & 0.005 & 0.4 & 2.59 & 0.020 & -1.3 & 2.1 \\
$0.10(\mathrm{~L} 3)$ & 1.7 & 2.39 & 0.020 & 0.4 & 2.60 & 0.015 & -1.6 & 2.1 \\
$0.43(\mathrm{~L} 1)$ & 1.2 & 2.40 & 0.020 & 2.0 & 2.59 & 0.060 & -1.2 & 3.2 \\
$0.75(\mathrm{~L} 3)$ & 1.3 & 2.40 & 0.024 & 1.8 & 2.58 & 0.040 & -1.0 & 3.1 \\
\hline
\end{tabular}


The results of the analytical procedure, are shown in Table II for two different glassy compositions of each glassy line. As shown in Table II, the results are quite similar for these two lines.

We must point out that by fitting a two-shells model, the total $\mathrm{N}^{\prime}+\mathrm{N}^{\prime \prime}$ neighbours number is equal to two for poor silver containing glasses (as in binary $\mathrm{As}_{0.50} \mathrm{Se}_{0.50}$ or $\mathrm{As}_{0.40} \mathrm{Se}_{0.60}$ glasses), and equal to three for silver enriched glasses (as in the $\mathrm{Ag}_{3} \mathrm{AsSe}_{3}$ crystalline phase).

\section{III.1.C - Silver K edge results}

The Fourier transform moduli of $\mathbf{k}^{3}$ weighted EXAFS spectra for the silver atoms for some glassy compositions are compared with the $\mathrm{Ag}_{3} \mathrm{AsSe}_{3}$ reference compound in figure 3 . The fitting results show, in both cases, that the silver atom is approximately dicoordinated by selenium atoms, whatever the silver composition, with a mean bond length equal to $2.54 \AA$. However, the Debye-Waller factor $(\Delta \sigma)$, which is related to the local disorder, is quite constant for the L1 line glasses although it increases for the L3 line glasses when silver is added.

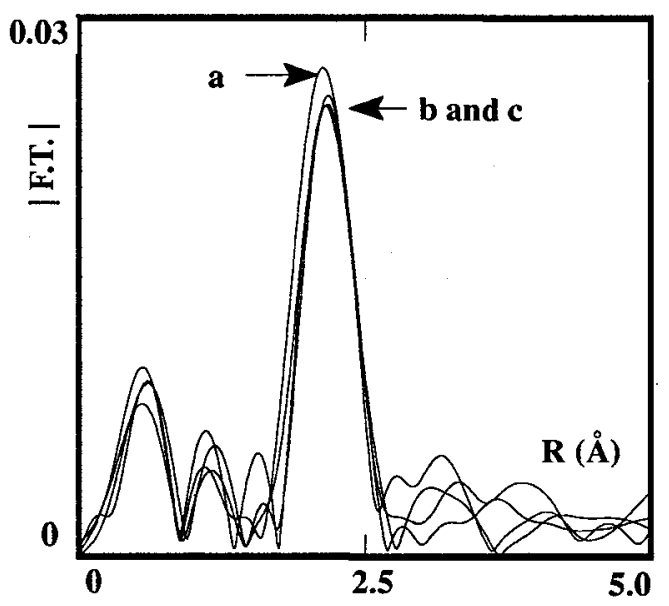

[L1]

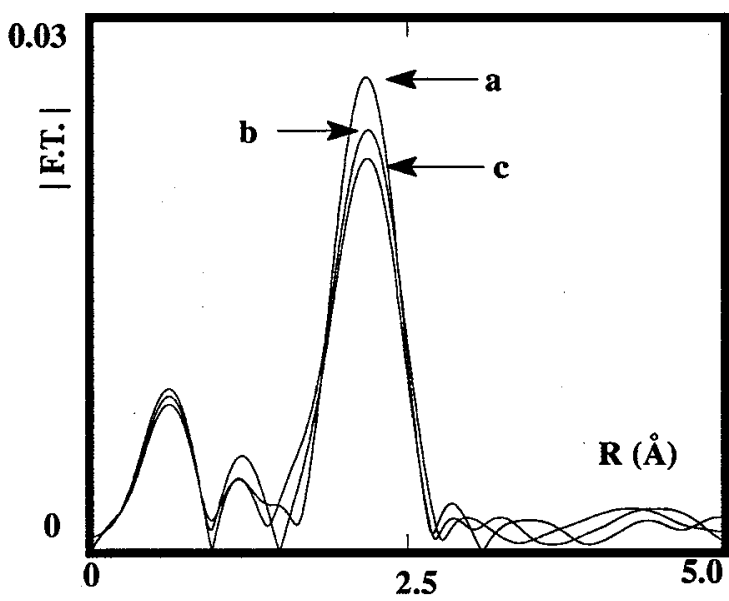

[L3]

Figure 3 - Fourier transform moduli (uncorrected for phase shift) at the silver K edge: [L1] glasses line: a: $\mathrm{Ag}_{3} \mathrm{AsSe}_{3}$ crystal, b: $\mathrm{x}=0.18$ and $\mathrm{c:} \mathrm{x}=0.43$, [L3] glasses line : $\mathrm{a}: \mathrm{Ag}_{3} \mathrm{AsSe}_{3}$ crystal, b: $\mathrm{x}=0.50$ and $\mathrm{c}: \mathrm{x}=0.75$.

\section{III.2- Comparison of $\mathrm{L3}$ selenide and $\mathrm{L} 2$ sulphide glasses lines}

The comparison between the L2 (sulphide) and L3 (selenide) glasses leads to two main points:

- the features observed around the arsenic and silver atoms are similar [4],

- due to technical limitations of the analysis, the sulphur $\mathrm{K}$ edge only give qualitative informations. However, we note the same structural evolutions as those observed for selenide when the modifier content increases.

\section{IV-Comparison of $\mathrm{Tg}$ and ionic conductivity: relationship with silver content}

Figure 4 presents the variation of $\mathrm{Tg}$ for each glass line versus the modifier content. The $\mathrm{Tg}$ variation is quite similar for L2 sulphide glasses and L3 selenide glasses: it decreases when the content of modifier increases. On the other hand, for $\mathrm{L} 1$ selenide glasses, after a quick diminution, Tg is quite constant for all glassy compositions. This seems to be correlated with our EXAFS results which have 
demonstrated that the behaviour is different between the L1 line and the L2 or L3 lines. In the case of the L1 line, the intensity of the Fourier transform around the arsenic and silver atoms does not change with the modifier content, whereas it presents a minimal values for $\mathrm{L} 2$ and $\mathrm{L} 3$ lines. This phenomena could be easily interpreted by the existence of $\mathrm{As}-\mathrm{As}$ homopolar bonds, as for the $\mathrm{As}_{0.50} \mathrm{Se}_{0.50}$ binary glassy composition, forming As-As-Se bonds which block the structure. This may explain the small variations of $\mathrm{Tg}$ for glasses along the $\mathrm{L} 1$ line.

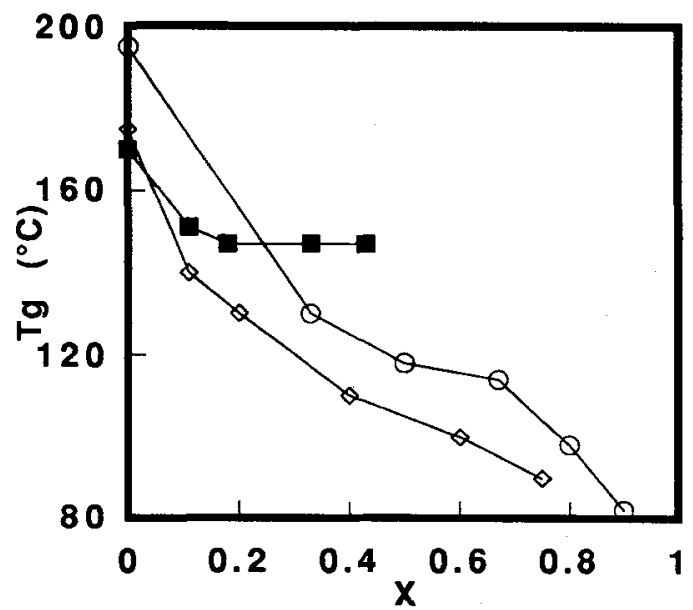

Figure 4 - Variation of $\mathrm{Tg}$ for: $\left(\mathrm{Ag}_{2} \mathrm{Se}\right)_{\mathbf{x}}(\mathrm{AsSe})_{1-\mathrm{x}}$ glasses (L1) ( $)^{[7]}$, $\left(\mathrm{Ag}_{2} \mathrm{~S}\right)_{\mathbf{x}}\left(\mathrm{As}_{2} \mathrm{~S}_{3}\right)_{1-\mathrm{x}}$ glasses (L2) ( 0 ) [8] and $\left(\mathrm{Ag}_{2} \mathrm{Se}\right)_{\mathbf{x}}\left(\mathrm{As}_{2} \mathrm{Se}_{3}\right)_{1-\mathrm{x}}$ glasses (L3) (a), versus $\mathrm{Ag}_{2}(\mathrm{Se}, \mathrm{S})$ content.

The electrical characteristics, Log $\sigma$ (ionic conductivity dc, figure 5a) and Ea (activation energy $\mathrm{dc}$, figure $5 \mathrm{~b}$ ) versus the silver atomic content per $\mathrm{cm}^{3}$, are presented for the selenide and sulphide glasses. In both cases, classical results are obtained: an increase in the conductivity and a decrease in the activation energy are observed with higher silver loading. Furthermore, the variation of $\log \sigma$ and $E_{a}$ are quite similar for selenide and sulphide glasses, within experimental errors.



(a)



(b)

Figure 5 - (a): Variation of the log $\sigma$ and (b) ): variation of the Ea for $\left(\mathrm{Ag}_{2} \mathrm{Se}\right)_{\mathbf{x}}(\mathrm{AsSe})_{1-\mathrm{x}}$ glasses

(L1) (a) [1], $\left(\mathrm{Ag}_{2} \mathrm{~S}\right)_{\mathbf{x}}\left(\mathrm{As}_{2} \mathrm{~S}_{3}\right)_{1-\mathrm{x}}$ glasses (L2) (o ) [8,9] and $\left(\mathrm{Ag}_{2} \mathrm{Se}\right)_{\mathrm{x}}\left(\mathrm{As}_{2} \mathrm{Se}_{3}\right)_{1-\mathrm{x}}$ glasses

(L3) ( $\mathrm{\theta})$, with the increases of silver atom $/ \mathrm{cm}^{3}$.

Recently, V.M. Lledos et al. [10] and A. Pradel and M. Ribes [11], have pointed out such a similarity existing in the electrical measurements of selenide and sulphide glasses for different systems. They have shown that this similarity is in agreement with the models proposed either by Ravaine and 
Souquet (R-S) [12] or by Anderson and Stuart (A-S) [13], to explain the variations of activation energy.

In the (R-S) model, the main parameter which governs the ion movement is the anion polarisability, which is comparable for sulphur and selenide glasses [10]. This explains then the similar conductivities noticed on sulphide and selenide glasses here studied.

If we consider the (A-S) model, the variation of the activation energy takes into account two contributing factors (electrostatic and elastic) and is related to different parameters characteristic of the vitreous matrix $[9,10]$. Although some of these parameters cannot be experimentally determinated, Anderson and Stuart demonstrate that the electrostatic contribution factor depends mainly on the covalency parameter. The dielectric constant may be identified to this covalency parameter and it presents similar values for the sulphide and selenide glasses. Concerning the elastic contribution factor, the authors consider that via the shear modulus $\mathrm{G}$ it can be related to the $\mathrm{Tg}$ of glasses.

We do not find any relation between the $\mathrm{Tg}$ (figure 4) and the electrical parameters variations (figure 5), which suggests that the elastic part plays a minor role in the conductivity properties, as observed by other authors $[10,11]$.

Concerning our EXAFS studies, the similarity of $\sigma$ and $\mathrm{E}_{\mathrm{a}}$ for these selenide and sulphide glasses indicates that these parameters are not significantly influenced by the existence of different degree of local structural disorder.

\section{V- Conclusion}

In this work the important role of the network former in the local structure of the Ag-As-Se ternary glasses is evidenced. The different behaviour of the Debye-Waller factor observed around the arsenic and silver atoms is explained by the existence of As-As homopolar bonds in the $\left(\mathrm{Ag}_{2} \mathrm{Se}\right)_{\mathrm{x}}(\mathrm{AsSe})_{1-\mathrm{x}}$ (L1) glasses, which blocks the structure, limiting problably the depolymerisation effect. A relation between homopolar bonding and the small variation in the $\mathrm{Tg}$ for $\mathrm{L} 1$ glasses is thus proposed. Furthermore, we have shown the importance of the electrostatic contribution factor on the activation energy.

We acknowledge helpful discussions with M. Ribes and A. Pradel. One of us (V.M.) is supported by a $\mathrm{Ph} . \mathrm{D}$. fellowship from CAPES, delivered by the Brazilian governement.

\section{References}

[1] CARCALY C. and HOUPHOUET-BOIGNY D. , Journal of Non-Cryst. Solids 86 (1986) 271.

[2] FRUMAR M. , WAGNER T. and VICEK M. , Eur. J. Solid State Inorg. Chem. 28, (1991) 1193.

[3] KOLOBOV A.V. and ELLIOT S.R., Advances in Physics 10, ${ }^{\circ} 5$, (1991) 625.

[4] MASTELARO V., DEXPERT H. and BENAZETH S., To be published in the proccedings of E-MRS Spring Meeting - Solid State Ionics, Stransbourg - France (1991).

[5] MASTELARO V., BENAZETH S., DEXPERT H., IBANEZ, A. and OLLITRAULT - FICHET R., submitted to the Journal of Non-Cryst. Solids.

[6] PRADEL A., PAGNIER T. and RIBES M., Solid State Ionics 17, (1985) 147.

[7] HOUPHOUET-BOIGNY D., Thèse de doctorat, Université d'A bidjan (1985).

[8] KAWAMOTO Y., NAGURA N. and TSUCHIHASHI S., J. Am. Ceram. Soc. 56(5), (1973) 289.

[9] JUN L., VIDEAU J.J., TANGUY B., PORTIER J., REAU J.M. and HAGENMULLER P., Mat. Res. Bull. 23, (1988) 1315.

[10] LLEDOS V.M., PRADEL A. and RIBES M., to be published in the European Journal of Solid State Chemistry.

[11] PRADEL A. and RIBES M. Journal of Solid State Chemistry 96, (1992) 247.

[12] RAVAINE D. and SOUQUET J.L., Phys. Chem. Glasses 18, (1977) 27.

[13] ANDERSON O.L. and STUART D.A., J. Am. Ceram. Soc 37, (1954) 573. 